\title{
Feasibility of landiolol and bisoprolol for prevention of atrial fibrillation after coronary artery bypass grafting: A pilot study
}

\author{
Akira Sezai, MD, PhD, ${ }^{a}$ Tishiko Nakai, MD, PhD, ${ }^{b}$ Mitsumasa Hata, $\mathrm{MD}, \mathrm{PhD},{ }^{\mathrm{a}}$ \\ Isamu Yoshitake, $\mathrm{MD}, \mathrm{PhD},{ }^{\mathrm{a}}$ Motomi Shiono, $\mathrm{MD}, \mathrm{PhD},{ }^{\mathrm{a}}$ Satoshi Kunimoto, $\mathrm{MD}, \mathrm{PhD},{ }^{\mathrm{b}}$ and \\ Atsushi Hirayama, $\mathrm{MD}, \mathrm{PhD}^{\mathrm{b}}$
}

\begin{abstract}
Background: We previously performed a trial of intravenous landiolol hydrochloride during and after cardiac surgery (the PASCAL trial) and demonstrated a preventive effect on postoperative atrial fibrillation (AF). In the present study, we investigated the efficacy of increasing the dose and administration period of landiolol for prevention of postoperative $\mathrm{AF}$, as well as the effect of oral bisoprolol in the early postoperative period.
\end{abstract}

\begin{abstract}
Patients and Methods: A total of 105 patients who underwent coronary artery bypass grafting were randomized to 3 groups: a group receiving intravenous landiolol perioperatively at $5 \mu \mathrm{g} / \mathrm{kg} / \mathrm{min}$ for 3 days (group L), a group receiving oral bisoprolol postoperatively together with landiolol (group LB), and a control group without beta-blocker therapy (group C). The primary end point was the presence/absence of postoperative AF. Secondary end points were (1) the early clinical outcome, (2) hemodynamics, (3) cardiac enzymes (creatine kinase isoenzyme MB, troponin-I, and human heart fatty acid-binding protein), (4) high-sensitivity C-reactive protein (hs-CRP) and pentraxin-3, (5) asymmetric dimethylarginine (ADMA), and (6) brain natriuretic peptide.
\end{abstract}

Results: Postoperative AF occurred in $14.5 \%$ of group L, $9.1 \%$ of group LB, and $35.3 \%$ of group C. A significant difference was observed between groups LB and C. Significantly higher levels of troponin-I, human heart fatty acid-binding protein, hs-CRP, pentraxin-3, and ADMA were noted in group C than in groups L and LB.

Conclusions: Landiolol and bisoprolol prevented postoperative AF. The anti-ischemic, anti-inflammatory, and anti-oxidant effects of these beta-blockers presumably inhibited the onset of AF. (J Thorac Cardiovasc Surg 2012;144:1241-8)

Atrial fibrillation (AF) is the most common complication of cardiac surgery with a reported incidence of $16 \%$ to $85 \% .^{1-5}$ Postoperative AF not only causes problems after surgery but also has a marked influence on long-term mortality, ${ }^{6-8}$ so that its prevention important. Several studies on the prevention of postoperative AF have been reported. ${ }^{5,8-11}$ According to the American College of Cardiology/ American Heart Association/European Society of Cardiology (ACC/AHA/ESC) guidelines, there is level A evidence for amiodarone and oral $\beta$-blockers (in patients without contraindications to $\beta$-blocker therapy), with

\footnotetext{
From the Department of Cardiovascular Surgery, ${ }^{\mathrm{a}}$ Department of Cardiology, ${ }^{\mathrm{b}}$ Nihon University School of Medicine, Tokyo, Japan.

This study was supported by a grant for scientific research from the Japanese Ministry of Education, Culture, Sports, Science and Technology (No. 21591805), a grant from Takeda Science Foundation, a Nihon University School of Medicine Alumni 60th Anniversary Medical Research Grant, and a Nihon University School of Medicine Foundation 50th Anniversary Medical Research Grant.

Disclosures: Authors have nothing to disclose with regard to commercial support.

Clinical Trial Registration Information: UMIN (http://www.umin.ac.jp/), Study ID: UMIN00000 2489.

Received for publication June 15, 2011; revisions received May 11, 2012; accepted for publication June 15, 2012; available ahead of print Aug 2, 2012.

Address for reprints: Akira Sezai, MD, PhD, The Department of Cardiovascular Surgery, Nihon University School of Medicine, 30-1 Oyaguchi-kamimachi, Itabashi-ku, Tokyo 173-8610, Japan (E-mail: asezai.med@gmail.com). $0022-5223 / \$ 36.00$

Copyright (c) 2012 by The American Association for Thoracic Surgery http://dx.doi.org/10.1016/j.jtcvs.2012.06.042
}

prophylactic administration being recommended. ${ }^{12}$ Intravenous infusion of $\beta$-blockers has been reported to be more effective than oral administration, but few randomized controlled trials have compared these 2 routes of administration, probably because intravenous $\beta$-blockers are more likely to cause hypotension and heart failure than oral $\beta$-blockers. ${ }^{13,14}$ Landiolol is an ultra-short-acting $\beta$-blocker that was developed in Japan and has been used clinically since 2002 . Currently, it is only approved in Japan. Landiolol has a shorter half-life, higher $\beta_{1}$ selectivity, and weaker negative inotropic effect than other intravenous $\beta$-blockers, so that it is unlikely to cause hypotension. ${ }^{15-17}$ $\mathrm{We}^{18}$ previously performed an international randomized controlled trial (Prevention of Atrial Fibrillation in Patients Having Cardiac Surgery With Landiolol Hydrochloride [PASCAL]) that investigated whether or not landiolol could prevent postoperative AF. Intravenous infusion of landiolol for 2 days at $2 \mu \mathrm{g} / \mathrm{kg} / \mathrm{min}$ was compared with placebo, showing no adverse effects on hemodynamics and significant reduction of postoperative $\mathrm{AF}(10 \%$ in the landiolol group vs $34 \%$ in the placebo group). Thus, we confirmed that landiolol could be administered safety both during and after cardiac surgery with a preventive effect on postoperative AF. The present study (Effect of Beta-Blockers for Prophylaxis of Atrial Fibrillation After Coronary Artery Bypass Grafting With Intravenous Landiolol Hydrochloride 


$\begin{array}{ll}\text { Abbreviations and Acronyms } \\ \text { ACC } & \text { American College of Cardiology } \\ \text { ADMA } & =\text { asymmetric diemthylarginine } \\ \text { AF } & \text { atrial fibrillation } \\ \text { AHA } & =\text { American Heart Association } \\ \text { BABYLON = } & \text { Effect of Beta-Blockers for } \\ & \text { Prophylaxis of Atrial Fibrillation } \\ & \text { After Coronary Artery Bypass } \\ & \text { Grafting With Intravenous Landiolol } \\ & \text { Hydrochloride and Oral Bisoprolol } \\ & \text { Administration } \\ = & \text { brain natriuretic peptide } \\ = & \text { blood pressure } \\ \text { BNP } & \text { coronary artery bypass grafting } \\ \text { BP } & \text { creatine kinase isoenzyme Mb } \\ \text { CABG } & \text { cardiopulmonary bypass } \\ \text { CK-MB } & \text { European Society of Cardiology } \\ \text { CPB } & =\text { heart rate } \\ \text { ESC } & =\text { high-sensitivity C-reactive protein } \\ \text { HR } & \text { intensive care unit } \\ \text { Hs-CRP } & \text { Prevention of Atrial Fibrillation in } \\ \text { ICU } & \text { Patients Having Cardiac Surgery } \\ \text { PASCAL } & \text { With Landiolol Hydrochloride } \\ & =\text { pentraxin-3 } \\ \text { PTX-3 } & \end{array}$

and Oral Bisoprolol Administration [BABYLON] trial) was undertaken to determine whether or not a higher dose and longer infusion of landiolol, as well as adding oral bisoprolol in the early postoperative period, could more effectively prevent AF after cardiac surgery.

\section{PATIENTS AND METHODS \\ Study Protocol}

Landiolol has been approved by the Japanese Ministry of Health, Labor and Welfare for the treatment of postoperative tachyarrhythmias, but its prophylactic use is still not approved, whereas bisoprolol is approved only for treating hypertension and heart failure in Japan. Therefore, the Ethics Committee of Nihon University School of Medicine Itabashi Hospital assessed and approved this study. We orally explained the details of the study using materials prepared by the ethics committee to all patients who were scheduled for coronary artery bypass grafting (CABG) under cardiopulmonary bypass (CPB), as well as to their families, and obtained written informed consent from the subjects. This study was registered with the University Hospital Medical Information Network (UMIN) (study ID: UMIN000002489).

The subjects were patients who underwent CABG under CPB after giving informed consent. Patients were randomized into 3 groups by the lottery method. One group was administered $5 \mu \mathrm{g} / \mathrm{kg} / \mathrm{min}$ of landiolol (Ono Pharmaceutical Co, Ltd, Osaka, Japan) intravenously for 3 days, starting from the completion of central anastomosis (group L). The second group was administered landiolol by the same regimen as well as oral or gavage administration of bisoprolol ( $2.5 \mathrm{mg} /$ day $)$ from the day after surgery (group LB). The third group did not receive $\beta$-blocker therapy (group C). Intravenous administration of landiolol and placebo was done under double-blind conditions, and the medical staff and study assistants were single blinded for oral administration. Right atrial pacing was initiated when the heart rate (HR) was 90 beats/min or less, and it was discontinued after 72 hours. CABG was done under CPB with a Jostra HL-20 (Jostra Inc, Hirrlingen, Germany). Nonpulsatlie perfusion was used with hypothermia (rectal temperature, $34^{\circ} \mathrm{C}$ ). Intermittent aortic crossclamping was performed without any cardioplegic solution. In all patients, the left internal thoracic artery was anastomosed to the left anterior descending branch of the left coronary artery, while radial artery or saphenous vein grafts were used at other sites. Exclusion criteria for this study were cardiogenic shock, sinus bradycardia ( $\leq 50$ beats/min at rest), second- or third-degree atrioventricular block, hypothyroidism or hyperthyroidism, arrhythmias, and offpump surgery.

On the basis of the results of the PASCAL trial, we planned to enroll 200 patients (at least 60 in each group) to achieve sufficient statistical power for the primary end point. Use of $\beta$-blockers for the prevention of postoperative $\mathrm{AF}$ is recommended by the ACC/AHA/ESC guidelines. However, the efficacy of landiolol for postoperative AF has not been investigated in countries other than Japan. Therefore, it was decided that if a significant difference in the incidence of AF or complications was detected by a pilot study enrolling 100 patients, the ethics committee would examine whether the study should be continued or not.

\section{End Points}

The primary end point was the presence or absence of AF within 1 week after surgery. The secondary end points were (1) operative mortality and complications; (2) systolic and diastolic blood pressure (BP) and HR; (3) creatine kinase isoenzyme $\mathrm{Mb}(\mathrm{CK}-\mathrm{MB})$ (in the intensive care unit [ICU] recovery room, after 3 hours in the recovery room, on postoperative day 1 , and on day 3 ), troponin-I, and human heart fatty acid binding protein (in the ICU recovery room, and on postoperative days 1 and 3 ) as biomarkers of ischemia-reperfusion injury; (4) high-sensitivity C-reactive protein (hs-CRP) (preoperatively, on postoperative days 1 and 3, weeks 1 and 2, and months 1 and 3), and pentraxin-3 (PTX-3) (preoperatively, in the ICU recovery room, on postoperative days 1 and 3, and week 1) as biomarkers of inflammation; (5) asymmetric diemthylarginine (ADMA) (preoperatively, in the ICU recovery room, on postoperative days 1 and 3, and week 1) as a biomarker of oxidative stress; and (6) brain natriuretic peptide (BNP) (preoperatively, on postoperative days 1 and 3, weeks 1 and 2, and months 1 and 3). Blood samples for the measurement of PTX-3 and ADMA were freeze-dried, with PTX-3 being assayed by enzyme-linked immunosorbent assay and ADMA being measured by high-performance liquid chromatography. Until 72 hours postoperatively, rapid atrial pacing at 90 beats/min was performed when the HR was less than 90 beats/min. In patients receiving atrial pacing, BP and $\mathrm{HR}$ were measured after pacing was stopped temporarily.

HR was monitored continuously for 1 week postoperatively and the presence or absence of AF was observed. AF was defined as being present if this arrhythmia persisted for more than 5 minutes or affected hemodynamics and required treatment. Antiarrhythmic agents and digitalis were not administered at the resumption of postoperative oral drug therapy, but administration was commenced if arrhythmic episodes occurred during the postoperative period. Postoperative complications were classified as central nervous system disorders, circulatory disorders (low output syndrome, heart failure, perioperative myocardial infarction, and refractory arrhythmia), respiratory failure, acute renal failure (requiring dialysis), gastrointestinal disorders (eg, bleeding, ileus, and hepatic dysfunction requiring hyperalimentation), infections (eg, septicemia, pneumonia, and mediastinitis), and other disorders requiring long-term management in the ICU.

\section{Statistical Analysis}

Results are expressed as the mean \pm standard deviation. For parametric and nonparametric data, the significance of differences was determined by using the Student $t$ test and Fisher's exact test, respectively. Other data were analyzed by repeated-measures analysis of variance, with a post-hoc 
Scheffé test. All analyses were conducted with SPSS software (SPSS Inc, Chicago, Ill).

\section{RESULTS \\ Subject Disposition}

A total of 105 patients were enrolled. Four patients were excluded because they had off-pump CABG or underwent another cardiac operation concomitantly, after which 34 were assigned to group L, 33 to group LB, and 34 to group C. Treatment was not discontinued because of hypotension or bradycardia in patients from any of the groups, and the trial was completed by all subjects.

\section{Baseline Characteristics}

The baseline characteristics are shown in Table 1. There were no significant differences among the 3 groups with respect to age, sex, body surface area, EuroSCORE, diagnosis, emergency surgery, risk factors, complications, preoperative oral medications, ejection fraction, BNP, systolic and diastolic BP, HR, hs-CRP, ADMA, and PTX-3 (Table 1 and Figures 1-4).

\section{Intraoperative and Postoperative Parameters}

No significant differences among the 3 groups were noted with respect to the aortic perfusion time, extracorporeal circulation time, number of bypasses, number of doses of catecholamines, postoperative oral medications, ejection fraction obtained by echocardiography at 1 week postoperatively, and days of hospitalization (Table 2).

\section{Primary End Point}

Postoperative AF was detected in $5(14.7 \%)$ patients from group L, $3(9.1 \%)$ patients from group LB, and 12 $(35.3 \%)$ patients from group C. There were no significant differences between group $\mathrm{L}$ and the other 2 groups, but group LB showed a significantly lower incidence of AF than group $\mathrm{C}(P=.017)$. The timing of the onset of $\mathrm{AF}$ did not differ among the 3 groups $(P=.2445)$. Also, the incidence of $\mathrm{AF}$ within 3 days after discontinuing intravenous landiolol or placebo (physiologic saline) showed no significant difference $(P=.552)$, with the rate being $60 \%$ in group $\mathrm{L}, 75 \%$ in group $\mathrm{LB}$, and $33.3 \%$ in group $\mathrm{C}$.

\section{Secondary End Points}

Death and complications. Postoperative death (Table 2) occurred in 1 patient from group L (mediastinitis) and 1 patient from group C (arrhythmia), and there was no significant difference in the death rate among the 3 groups $(P=1.00)$. Postoperative complications affected 2 patients from group $\mathrm{L}$ (myocardial infarction and mediastinitis in 1 case each), 2 patients from group LB (perioperative myocardial infarction and acute renal failure in 1 case each), and 3 patients from group C (low-output syndrome, heart
TABLE 1. Comparison of clinical characteristics and measured data

\begin{tabular}{|c|c|c|c|c|}
\hline & L group & LB group & C group & $\begin{array}{c}P \\
\text { value }\end{array}$ \\
\hline No. & 34 & 33 & 34 & \\
\hline Age (y) & $68.5 \pm 9.6$ & $68.1 \pm 8.2$ & $68.2 \pm 7.5$ & .9742 \\
\hline $80 \mathrm{y}<$ & 3 & 2 & 2 & 1.00 \\
\hline $75 y<$ & 8 & 9 & 6 & .6380 \\
\hline $70 \mathrm{y}<$ & 16 & 16 & 14 & .9073 \\
\hline Gender (male/female) & $26: 8$ & $26: 7$ & $30: 4$ & .4811 \\
\hline Body surface area $\left(\mathrm{m}^{2}\right)$ & $1.67 \pm 0.15$ & $1.63 \pm 0.17$ & $1.66 \pm 0.14$ & .6215 \\
\hline EuroSCORE & $7.2 \pm 3.4$ & $6.1 \pm 3.3$ & $6.1 \pm 3.8$ & .3437 \\
\hline EuroSCORE $>8$ & 15 & 13 & 7 & .0972 \\
\hline EuroSCORE $>10$ & 8 & 4 & 7 & .5302 \\
\hline \multicolumn{5}{|l|}{ Diagnosis } \\
\hline $\begin{array}{l}\text { Acute myocardial } \\
\text { infarction }\end{array}$ & 3 & 2 & 1 & .7567 \\
\hline $\begin{array}{l}\text { Old myocardial } \\
\text { infarction }\end{array}$ & 9 & 14 & 12 & \\
\hline Unstable angina & 17 & 13 & 14 & \\
\hline Stable angina & 5 & 4 & 7 & \\
\hline Emergency surgery & 14 & 7 & 7 & .1309 \\
\hline \multicolumn{5}{|l|}{ Risk factors } \\
\hline Diabetes mellitus & 16 & 19 & 14 & .4309 \\
\hline Hypertension & 26 & 26 & 28 & .8681 \\
\hline Hyperlipidemia & 17 & 12 & 17 & .4348 \\
\hline Obesity & 7 & 6 & 5 & .8543 \\
\hline Smoking & 13 & 11 & 13 & .9012 \\
\hline COPD & 2 & 1 & 2 & 1.00 \\
\hline $\begin{array}{l}\text { Cerebrovascular } \\
\text { disease }\end{array}$ & 3 & 3 & 1 & .6254 \\
\hline Chronic renal failure & 8 & 13 & 16 & .1148 \\
\hline Hemodialysis & 4 & 5 & 6 & .8353 \\
\hline \multicolumn{5}{|l|}{ Oral medications } \\
\hline ARB & 16 & 15 & 18 & .9036 \\
\hline ACE-I & 3 & 5 & 1 & .1861 \\
\hline $\mathrm{Ca}$ antagonist & 11 & 13 & 15 & .6049 \\
\hline Beta-blocker & 9 & 7 & 9 & .8785 \\
\hline Aldosterone blocker & 1 & 3 & 2 & .5245 \\
\hline Statin & 14 & 14 & 16 & .9065 \\
\hline Ejection fraction $(\%)$ & $60.4 \pm 10.1$ & $53.9 \pm 14.5$ & $60.0 \pm 13.6$ & .0780 \\
\hline
\end{tabular}

failure, and arrhythmia in 1 case each). There were no significant differences of complications among the 3 groups $(P=1.00)$.

Hemodynamics. No significant differences of preoperative systolic and diastolic BP and HR were observed among the 3 groups (Figure 1). There were also no differences of BP among the 3 groups during the postoperative course. Postoperative pacing was done for 28 patients in group L, 27 in group LB, and 23 in group $\mathrm{C}$, with no significant difference among the 3 groups $(P=.2898)$. On postoperative days 0 to 4 , the HR showed no significant differences when groups L and LB were compared with group C. On postoperative day 7 , however, group LB had a significantly lower HR than groups $\mathrm{L}$ and $\mathrm{C}(P=.002)$. 


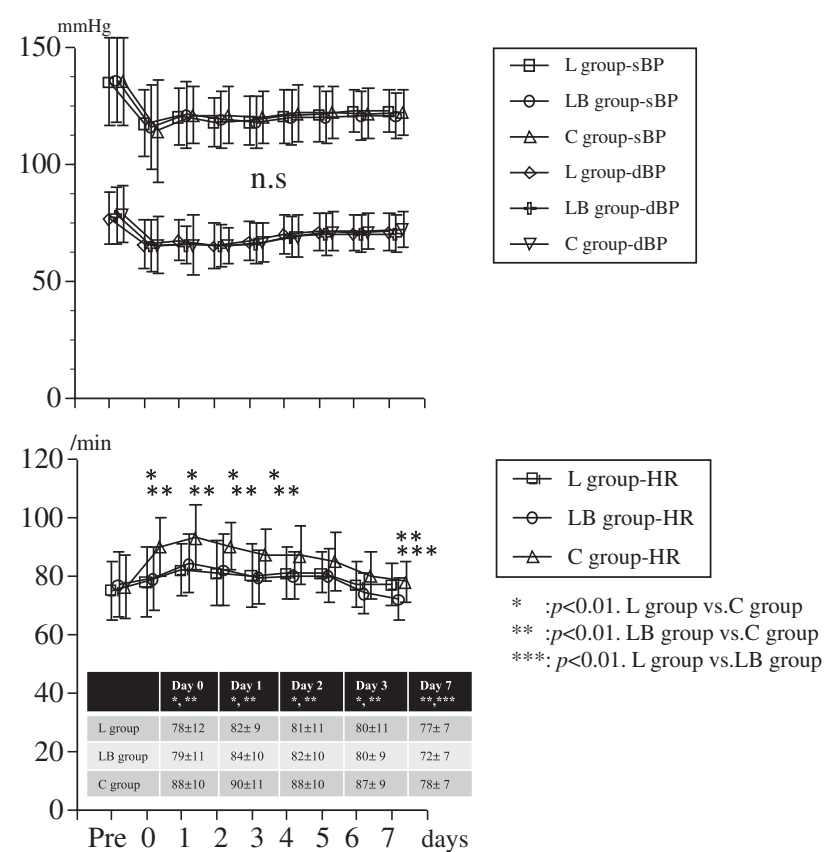

FIGURE 1. Hemodynamic profile (systolic and diastolic blood pressure [upper] and heart rate [lower]). No significant differences in systolic and diastolic blood pressure were found among the groups, but heart rate was significantly lower in the $\mathrm{L}$ group and LB group than in the $\mathrm{C}$ group from postoperative day 0 to day 4 . On postoperative day 7 , the value was significantly lower in the LB group than in the L group and $\mathrm{C}$ group. $s B P$, Systolic blood pressure; $d B P$, diastolic blood pressure; $H R$, heart rate; n.s., not significant.

Biomarkers of myocardial ischemia. On postoperative day 2, (Figure 2) group L had a significantly lower CKMB level than group $\mathrm{C}(P=.0359)$. On postoperative day 3 , groups L and LB both had significantly lower CK-MB levels than group $\mathrm{C}$ (group L vs group $\mathrm{C}, P=.0059$; group LB vs group $\mathrm{C}, P=.0475$ ). Troponin-I showed significant differences among the 3 groups in the ICU recovery room $(P=.0103)$, with groups $\mathrm{L}$ and LB having significantly lower values than group $\mathrm{C}$ (group $\mathrm{L}$ vs group $\mathrm{C}$, $P=.0166$; group $\mathrm{LB}$ vs group $\mathrm{C}, P=.005)$. In the recovery room, groups L and LB had significantly lower human heart fatty acid binding protein levels than group $\mathrm{C}$ (group L vs group $\mathrm{C}, P=.0246$; group $\mathrm{LB}$ vs group $\mathrm{C}, P=.0216$ ). On postoperative day 1 , groups L and LB also had significantly lower values than group $\mathrm{C}$ (group $\mathrm{L}$ vs group $\mathrm{C}$, $P=.001$; group LB vs group $\mathrm{C}, P=.038$ ).

Biomarkers of inflammation. Preoperative values of these biomarkers did not show any significant differences among the 3 groups (Figure 3). On postoperative day 3, group L and group LB had significantly lower hs-CRP levels than group $\mathrm{C}$ (group $\mathrm{L}$ vs group $\mathrm{C}, P=.0155$; group LB vs group $\mathrm{C}, P=.0134$ ). In postoperative week 1 , groups $\mathrm{L}$ and $\mathrm{LB}$ also showed significantly lower values than group $\mathrm{C}$ (group L vs group $\mathrm{C}, P=.0051$; group LB vs group $\mathrm{C}$,
$P=.0003$ ). In postoperative week 2 , however, group LB had a significantly lower value than groups $\mathrm{L}$ or $\mathrm{C}$ (group LB vs group L, $P=.0248$; group LB vs group C, $P=.0039$ ). On postoperative day 1 , groups $L$ and $L B$ had significantly lower PTX-3 levels than group C (group L vs group $\mathrm{C}, P=.0001$; group $\mathrm{LB}$ vs group $\mathrm{C}, P=.0001$ ), and group LB also had a significantly lower value than group $\mathrm{L}$ (group LB vs group $\mathrm{L}, P=.0009$ ). On postoperative day 3 , groups L and LB again showed significantly lower values than group $\mathrm{C}$ (group $\mathrm{L}$ vs group $\mathrm{C}$, $P=.0001$; group LB vs group $\mathrm{C}, P<.0001$ ), and group LB also had a significantly lower value than group L (group $\mathrm{LB}$ vs group $\mathrm{L}, P=.0449$ ). In postoperative week 1 , groups $\mathrm{L}$ and LB once again had significantly lower PTX-3 levels than group $\mathrm{C}$ (group L vs group $\mathrm{C}, P<.0001$; group LB vs group $\mathrm{C}, P<.0001$ ), while group LB group also had a significantly lower value than group L (group LB vs group L, $P=$.0135).

Biomarker of oxidative stress. On postoperative day 3, (Figure 3) groups L and LB had significantly lower ADMA levels than group $\mathrm{C}$ (group $\mathrm{L}$ vs group $\mathrm{C}$, $P=.0289$; group LB vs group $\mathrm{C}, P<.0001$ ), and group LB also had a significantly lower value than group L (group LB vs group $\mathrm{L}, P=.0138$ ). In week 1 , groups $\mathrm{L}$ and $\mathrm{LB}$ again showed significantly lower values than group $\mathrm{C}$ (group L vs group C, $P<.0001$; group LB vs group C, $P<.0001)$.

BNP. Preoperative BNP levels showed no significant differences among the 3 groups (Figure 4). On postoperative day 1 , month 1 , and month 3 , groups $\mathrm{L}$ and $\mathrm{LB}$ had significantly lower BNP values than group $\mathrm{C}(P<.0001)$, but there were no differences between groups $\mathrm{L}$ and LB.

When these results were presented to the ethics committee, although there are no guidelines regarding the prevention of postoperative AF in Japan, continuation of this trial was judged to be ethically problematic and it was stopped because there was a significant difference in the incidnece of AF between group $\mathrm{C}(\mathrm{n}=34)$ and group LB $(\mathrm{n}=75)(35.3 \%$ vs $9.1 \% ; P=.00339)$, while there was no difference of adverse events among the 3 groups.

\section{DISCUSSION}

The preventive effect of landiolol on AF after CABG was similar in this study and the previous PASCAL trial. AF occurred in $10 \%$ of patients treated with landiolol in the PASCAL trial, ${ }^{18}$ and the onset was almost always after landiolol had been discontinued, suggesting that postoperative AF might have been prevented if the dose of landiolol had been increased or the administration period had been prolonged. Therefore, the present study was performed as a continuation of the PASCAL trial. However, we found that the incidence of $\mathrm{AF}$ in the landiolol monotherapy group (group L) was $14 \%$ and there was no evidence that 


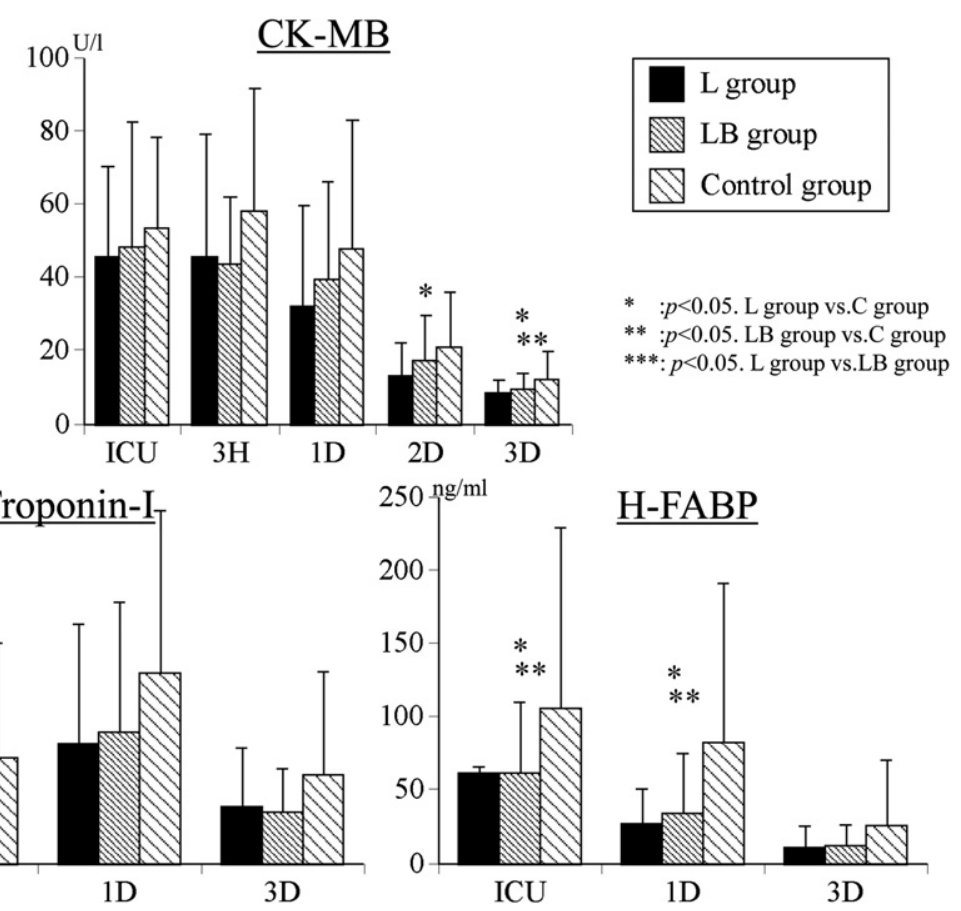

FIGURE 2. Changes in ischemic biomarker data: creatine kinase isoenzyme $\mathrm{Mb}(C K-M B)$ on postoperative days 2 and 3 , troponin-I in the intensive care unit $(I C U)$ recovery room and human heart fatty acid binding protein $(H-F A B P)$ in the ICU recovery room and on postoperative day 1 were significantly lower in the $\mathrm{L}$ group and LB group than in the $\mathrm{C}$ group.

increasing the dose of landiolol and extending its administration period improved the prevention of AF. In the 2 groups treated with landiolol, the incidence of AF after discontinuation of the drug was $50 \%$ for group $\mathrm{L}$ and $75 \%$ for group LB, with both rates being higher than that of 33.3\% in group C. Therefore, it appears that the occurrence of AF was prevented during infusion of landiolol. Because of the influence of various factors such as old age, cardiac function, chronic obstructive pulmonary disease, and left atrial diameter, postoperative AF cannot always be prevented by $\beta$-blockers. However, it appears that the anti-ischemic, anti-inflammatory, and antioxidant actions of $\beta$-blockers may inhibit $\mathrm{AF}$ based on our data regarding various biomarkers and HR. In group LB, hs-CRP in postoperative week 2 , PTX-3 on postoperative day 1 , day 3 , and week 1 , and ADMA on postoperative day 3 and week 1 were all significantly lower than in the other 2 groups. Also, the BNP level on postoperative day 1 , month 1 , and month 3 was significantly higher in group $C$ than in the other 2 groups. From our results, landiolol inhibits AF during surgery and in the early postoperative period, whereas early postoperative initiation of oral $\beta$-blocker therapy and continuation of oral therapy seems to be more important than increasing the dose of landiolol or extending its duration of administration.

When the protocol for this study was being drafted, selection of the oral $\beta$-blocker was a major problem. It has been shown that $\beta$-blockers reduce cardiac events in various large-scale studies of patients with acute myocardial infarction or chronic heart failure, and $\beta$-blockers without intrinsic sympathomimetic activity as well as lipid-soluble drugs have been recommended. ${ }^{19}$ In this study, we used bisoprolol as the oral $\beta$-blocker, inasmuch as it lacks intrinsic sympathomimetic activity, shows high lipophilicity, and has high $\beta_{1}$ selectivity similar to landiolol. In a comparative study of bisoprolol and carvedilol for congestive heart failure, Konishi and associates ${ }^{20}$ found no difference between the 2 drugs with respect to the cardiac event-free rate, but $\mathrm{AF}$ was significantly less frequent and BNP was lower in the bisoprolol group. Among the few studies that have assessed the effect of oral $\beta$-blockers on postoperative $\mathrm{AF}$, some reports have appeared recently. When they compared bisoprolol and carvedilol in patients with cardiac dysfunction undergoing CABG, Marazzi and associates ${ }^{21}$ found that the bisoprolol group had a significantly lower HR than the carvedilol group. They also found that the incidence of postoperative AF was lower in the bisoprolol group. In a comparative study of bisoprolol and amiodarone, which is known to be effective for prevention of postoperative AF together with $\beta$-blockers, Sleilaty and colleagues $^{22}$ detected $\mathrm{AF}$ in $12.7 \%$ of the bisoprolol group versus $15.3 \%$ of the amiodarone group, and the maximal ventricular rate was also lower in the bisoprolol group. In the present study, landiolol was infused perioperatively 

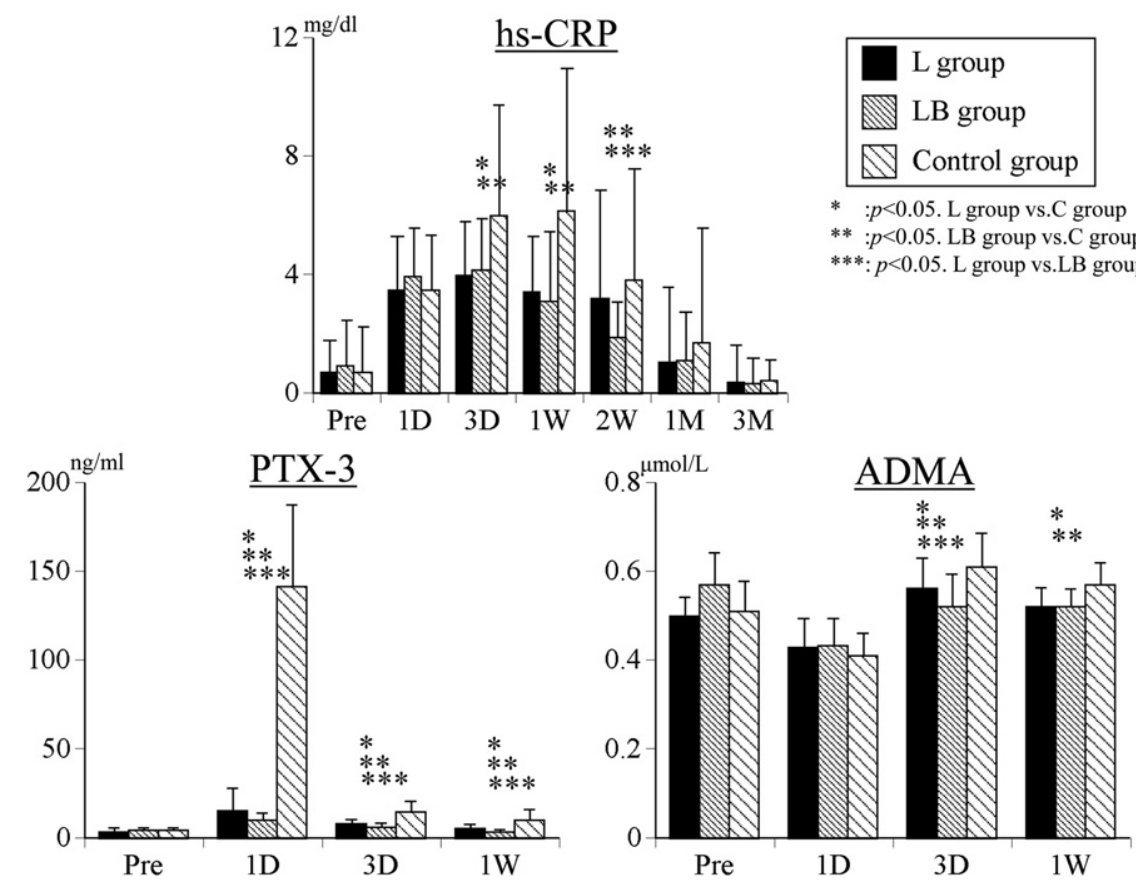

FIGURE 3. Changes in inflammation biomarkers and oxidative stress biomarkers $>$ high-sensitive C-reactive protein $(h s$ - $C R P)$ was significantly lower in the $\mathrm{L}$ group and LB group than in the $\mathrm{C}$ group at postoperative day 3, week 1 , and week 2 . In postoperative week 2 , the value in the LB group was significantly lower than those in the $\mathrm{L}$ group and $\mathrm{C}$ group. Pentraxin-3 (PTX-3) was significantly lower in the L group and LB group than in the $\mathrm{C}$ group at postoperative day 1, day 3, and week 1. It was also significantly lower in the LB group than in the L group. Asymmetric dimethylarginine (ADMA) was significantly lower in the $\mathrm{L}$ group and LB group than in the $\mathrm{C}$ group at postoperative day 3 and week 1 and also significantly lower in the LB group than in the L group in postoperative week 1 .

and we then continued treatment with oral bisoprolol, a highly selective $\beta_{1}$ receptor antagonist like landiolol, in group LB. There were no problems such as hypotension, bradycardia, or asthma, and no other safety problems were noted, whereas a marked prophylactic effect on postoperative AF was achieved.

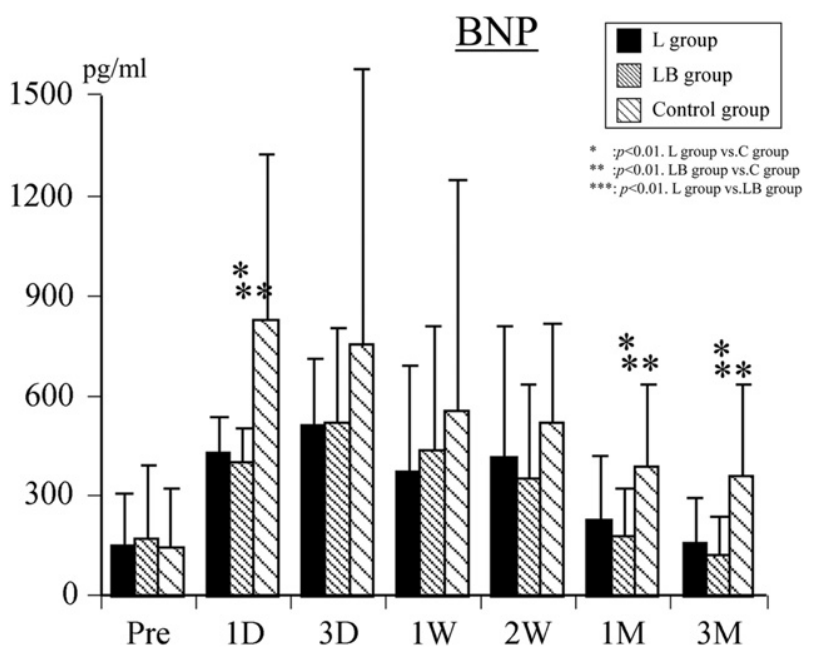

FIGURE 4. Changes in brain natriuertic peptide $(B N P)$. BNP was significantly lower in the L group and LB group than in the $\mathrm{C}$ group at postoperative day 1 , month 1 , and month 3 .
In this study, we analyzed PTX-3 as a marker of acute inflammation and measured ADMA as a biomarker for vascular endothelial function and oxidative stress. PTX-3 has been reported as a new biomarker for the severity and prognosis of acute myocardial infarction and heart failure. ${ }^{23,24}$ It has been reported that ADMA increases when endothelial function is impaired and serves as a marker for predicting cardiovascular events and $\mathrm{AF}^{25,26}$ In the present study, the data for these biomarkers demonstrated an antiinflammatory and antioxidant effect of $\beta$-blocker therapy. However, the clinical significance of these biomarkers is yet to be fully clarified, so further investigations will be needed.

The present findings and the results of the PASCAL trial suggest that landiolol may be a safe intravenous $\beta$-blocker for perioperative use with little risk of hypotension, which is a problem with existing treatment, but this study was not sufficiently powered to determine safety. Perioperative $\beta$-blocker therapy using landiolol and bisoprolol may prevent early postoperative AF owing to the antiinflammatory, anti-ischemic, and antioxidant effects of these drugs. Prophylactic administration of $\beta$-blockers is already recommended, and combining landiolol with an oral $\beta$-blocker may further reduce the incidence of postoperative AF. However, large-scale study would be needed to confirm the beneficial effect of landiolol. 
TABLE 2. Perioperative and postoperative findings

\begin{tabular}{lcccc}
\hline & & & & $\boldsymbol{P}$ \\
& L group & LB group & C group & value \\
\hline No. & 34 & 33 & 34 & \\
Days until AF & $3.7 \pm 1.4$ & $3.0 \pm 1.4$ & $2.5 \pm 1.3$ & .2445 \\
Mortality & 1 & 0 & 1 & 1.00 \\
Complications & 2 & 3 & 3 & 1.00 \\
No. of bypasses & $3.1 \pm 0.8$ & $3.4 \pm 1.0$ & $3.4 \pm 0.9$ & .1747 \\
ACCT (min) & $32.3 \pm 9.9$ & $36.4 \pm 23.9$ & $33.7 \pm 23.5$ & .4771 \\
ECCT (min) & $96.4 \pm 27.2$ & $103.1 \pm 31.0$ & $102.6 \pm 36.5$ & .6940 \\
Dopanine & 10 & 10 & 9 & .9619 \\
Dobutamine & 4 & 4 & 4 & 1.00 \\
Norepinephrine & 4 & 3 & 3 & 1.00 \\
Postoperative pacing & 28 & 27 & 23 & .2898 \\
Hospital stay (d) & $11.8 \pm 6.9$ & $11.1 \pm 3.0$ & $12.2 \pm 9.0$ & .8379 \\
Oral medications & & & & \\
$\quad$ ARB & 13 & 17 & 18 & .4457 \\
$\quad$ ACE-I & 0 & 0 & 0 & 1.00 \\
$\quad$ Ca antagonist & 13 & 12 & 19 & .2885 \\
$\quad$ Aldosterone & 26 & 27 & 26 & .5689 \\
$\quad$ blocker & & & & \\
$\quad$ Statin & 23 & 26 & 25 & .8681 \\
Ejection fraction $(\%)$ & $61.3 \pm 14.3$ & $58.0 \pm 12.9$ & $57.1 \pm 12.8$ & .4096 \\
\hline$A F$ Atin fib & & & &
\end{tabular}

$A F$, Atrial fibrillation; $A C C T$, aortic crossclamping time; $E C C T$, extracorporeal circulation time; $A R B$, angiotensin II receptor blocker; $A C E-I$, angiotensin-converting enzyme inhibitor; $\mathrm{Ca}$, calcium.

\section{Limitations}

The present study was single blind because use of landiolol was blinded, but there was no placebo for bisoprolol (only the medical and measurement staff were blinded).

On the basis of the results of the PASCAL trial, the power of test for postoperative AF was calculated, revealing that 60 patients or more per group were required. Accordingly, this study was designed to enroll 200 patients. However, after conducting an interim analysis of the initial 100 patients and submitting the results to the ethics committee, it was decided that the study should be terminated because of the very high incidence of AF in the placebo group. It is likely that statistically reliable data would have been obtained if we had been able to analyze 200 patients, but the truncated study did not yield sufficiently reliable results. Despite this, comparison of 2 active drug groups in the future should allow clarification of the effectiveness of oral and intravenous $\beta$-blockers for preventing postoperative AF, as well as the best protocol for switching to oral $\beta$-blockers. Another problem was that $25 \%$ of the subjects were using $\beta$-blockers preoperatively. Although there was no difference in preoperative use among the 3 groups, postoperative discontinuation of $\beta$-blocker therapy might have had an effect on the incidence of postoperative AF. Accordingly, a study of patients without preoperative $\beta$-blocker therapy should be done in the future. Moreover, our single-center design made it difficult to obtain sufficient patients, and a large-scale multicenter study is needed to obtain more meaningful results.

\section{References}

1. Villareal RP, Hariharan R, Liu BC, Kar B, Lee V, Elayda M, et al. Postoperative atrial fibrillation and mortality after coronary atrial bypass surgery. $J$ Am Col Cardiol. 2004;43:742-8.

2. Shen J, Shelly L, Zheng V, Buckley P, Damiano RJ, Schuessler RB. The persistent problem of new-onset postoperative atrial fibrillation: a singleinstitution experience over two decades. J Thorac Cardiovasc Surg. 2011;141: 559-70.

3. Sezai A, Hata M, Niino T, Kasamaki Y, Nakai T, Hirayama A, et al. Study of the factors related to atrial fibrillation after coronary artery bypass grafting: a search for a marker to predict the occurrence of atrial fibrillation before surgical intervention. J Thorac Cardiovasc Surg. 2009;137:895-900.

4. Nakai T, Lee RJ, Schiller NB, Bellows, Dzankic S, Reeves JR, et al. The relative importance of left atrial function versus dimension in predicting atrial fibrillation after coronary artery bypass graft surgery. Am Heart J. 2002;143:181-6.

5. Budeus M, Hennersdorf M, Perings S, Roehlen S, Schnitzler S, Felix O, et al. Amiodarone prophylaxis for atrial fibrillation of high-risk patients after coronary bypass grafting: a prospective, double-blind, placebo-controlled, randomized study. Eur Heart J. 2006;27:1584-91.

6. Bramer S, van Stranten AHM, Hamad MAS, Berrlkouw E, Martens EJ, Maessen JG. The impact of new-onset postoperative atrial fibrillation on mortality after coronary artery bypass grafting. Ann Thorac Surg. 2010;90: 443-50.

7. El-Chami MF, Kilgo P, Thourani V, Lattouf OM, Delurgio DB, Guyton RA, et al. New-onset atrial fibrillation predicts long-term mortality after coronary artery bypass graft. J Am Coll Cardiol. 2010;55:1370-6.

8. Kaw R, Hernandez AV, Masood I, Gillinov AM, Saliba W, Blackstone EH. Shortand long-term mortality associated with new-onset atrial fibrillation after coronary artery bypass grafting: a systematic review and meta-analysis. $J$ Thorac Cardiovasc Surg. 2011;141:1305-12.

9. Giri S, White CM, Dunn AB, Felton K, Freeman-Bosco L, Reddy P, et al. Oral amiodarone for prevention of atrial fibrillation after open heart surgery, the atrial fibrillation suppression trial (AFIST): randomized placebo-controlled trial. Lancet. 2001;357:830-6.

10. Shen J, Lall S, Zheng V, Buckley P, Damiano RJ, Schuessler RB. The persistent problem of new-onset postoperative atrial fibrillation: a single-institution experience over two decades. J Thorac Cardiovasc Surg. 2011;141:559-70.

11. Chen WT, Krishnan GM, Sood N, Kluger J, Coleman CI. Effect of statins on atrial fibrillation after cardiac surgery: a duration- and dose-response meta-analysis. J Thorac Cardiovasc Surg. 2010;140:364-72.

12. Fuster V, Ryden LE, Cannom DS, Crijns HJ, Curtis AB, Ellenbogen KA, et al. ACC/AHA/ESC 2006 guideline for management of patients with atrial fibrillation: a report of the American College of Cardiology/American Heart Association task force on practice guidelines and the European Society of Cardiology committee for practice guidelines (writing committee to revise the 2001 guidelines for the management of patients with atrial fibrillation): developed in collaboration with the European Heart Rhythm Association and Heart Rhythm Society. Circulation. 2006;114:e257-354.

13. Maniar PB, Balcetyye-Harris N, Tamis JE, Steinberg JS. Intravenous versus oral beta-blockers for prevention of post-CABG atrial fibrillation in high-risk patients identified by signal-averaged ECG: lessons of a pilot study. Card Electrophysiol Rev. 2003;7:158-61.

14. Mooss AN, Wurdeman RL, Mohiuddin EM, Reyes AP, Sugimoto JT, Scott W, et al. Esmolol versus diltiazem in the treatment of postoperative atrial fibrillation/atrial flutter after open heart surgery. Am Heart J. 2000; 140:176-80.

15. Iguchi S, Iwamura H, Nishizaki M, Hayashi A, Senokuchi K, Kobayashi K, et al Development of a highly cardioselective ultra short-acting beta-blocker, ONO 1101. Chem Pharm Bull (Tokyo). 1992;40:1462-9.

16. Sugiyama A, Takahara A, Hashimoto K. Electrophysiologic cardiohemodynamic and beta-blocking actions of a new ultra-short-acting beta blocker, ONO-1101, assessed by the in vivo canine model in comparison with esmolol. J Cardiovasc Pharmacol. 1999;34:70-7.

17. Sasao J, Tarver SD, Kindscher JD, Taneyama C, Benson KT, Goto H. In rabbits, landiolol, a new ultra-short-acting $\beta$-blocker, exerts a more potent negative chronologic effect and less effect on blood pressure than esmolol. Can J Anesth. 2001; 48:985-9. 
18. Sezai A, Minami K, Nakai T, Hata M, Yoshitake I, Wakui S, et al. Landiolol hydrochloride for prevention of atrial fibrillation after coronary artery bypass grafting: new evidence from the PASCAL trial. J Thorac Cardiovasc Surg. 2011;141:1478-87.

19. Hunt SA, Abraham WT, Chin MH, Feldman AM, Francis GS, Ganiats TG, et al. ACC/AHA 2005 guideline update for the diagnosis and management of chronic heart failure in the adult: a report of the American College of Cardiology/American Heart Association task force on practice guideline: developed in collaboration with the American College of Chest Physicians and the International Society for Heart and Lung Transplantation: endorsed by the Heart Rhythm Society. Circulation. 2005;112:e154-235.

20. Konishi M, Haraguchi G, Kimura S, Inagaki H, Kawabata M, Hachiya H, et al. Comparative effects of carvedilol vs. bisoprolol for severe congestive heart failure. Circ J. 2010;74:1127-34.

21. Marazzi G, Iellamo F, Volterrani M, Caminiti G, Madonna M, Arisi G, et al. Comparison of effectiveness of carvedilol versus bisoprolol for prevention of postdischarge atrial fibrillation after coronary artery bypass grafting in patients with heart failure. Am J Cardiol. 2011;107:215-9.
22. Sleilaty G, Madi-Jebara S, Yazigi A, Haddad F, Hayeck G, El Rassi I, et al. Postoperative oral amiodarone versus oral bisoprolol as prophylaxis against atrial fibrillation after coronary artery bypass graft surgery: a prospective randomized trial. Int J Cardiol. 2009;137:116-22.

23. Latini R, Maggioni AP, Peri G, Gonzini L, Lucci D, Mocarelli P, et al. Prognostic significance of the long pentraxin PTX3 in acute myocardial infarction. Circulation. 2004;110:2349-54.

24. Matusbara J, Sugiyama S, Nozaki T, Sugamura K, Konishi M, Ohba K, et al. Pentraxin 3 is a new inflammatory marker correlated with left ventricular diastolic dysfunction and heart failure with normal ejection fraction. J Am Coll Cardiol. 2011;57:861-9.

25. Goette A, Hammwoehner M, Bukowska A, Scalera F, Martens-Lobenhoffer J, Dobrev D, et al. The impact of rapid atrial pacing on ADMA and endothelial NOS. Int J Cardiol. 2012;26(154):141-6.

26. Xia W, Yin Z, Li J, Song Y, Qu X. Effects of rosuvastatin on asymmetric dimethylarginine levels and early atrial fibrillation recurrence after electrical cardioversion. PACE. 2009;32:1562-6. 